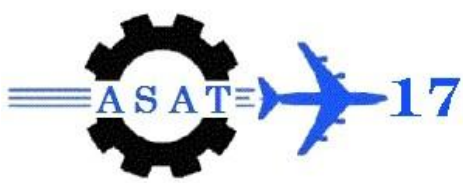

\title{
Effect of Ethanol-Diesel Fuel Blends on Autoignition and Combustion Characteristics in HCCI Engines
}

\author{
Aly M. Elzahaby ${ }^{*}$, Medhat Elkelawy ${ }^{\dagger}$, Hagar Alm-Eldin Bastawissi ${ }^{\ddagger}$, \\ Saad Mostafa El-Malla ${ }^{\S}$, Abdel Moneim M. Naceb ${ }^{\mathbb{I}}$
}

\begin{abstract}
The combustion process in homogeneous charge compression ignition (HCCI) is mainly controlled by the chemical kinetics reactions of the fuel-air mixture. So, the HCCI combustion process is sensitive to the charge temperature, pressure, and the mixture composition during the compression stroke. In the present work, the simulations results of the HCCI combustion are performed using a single zone model with detailed kinetic reaction mechanism. The simulation study is achieved to predict the auto-ignition timing and the combustion characteristics of the HCCI engine fueled with blends of ethanol and diesel at different volume percentage. The premixed ratio of the ethanol-diesel fuel blends is used in this study to control the auto-ignition timing and the combustion characteristics at a wide range of the engine load. The main pathway of this work is to study the influence of engine operating parameters which including the premixed ratio, fuel-air equivalence ratio on the combustion characteristics of HCCI engine. These effects are studied and traced through the simulation result data of the in-cylinder pressure, temperature, and heat release at different premixed ratios of ethanol-diesel fuels blends of $0,10,20,30,40$ and $50 \%$ (by volume). The engine speed is kept constant at 1500 RPM. The obtained results show that the increase of the premixed ratio of ethanol in diesel fuel blends in the range up to $50 \%$ will decrease the peak cylinder pressure and temperature and decrease the combustion duration.
\end{abstract}

Keywords: HCCI engine, Diesel/Ethanol Blends, Chemical Kinetics Mechanism

\section{Nomenclature}

$\begin{array}{ll}\text { ATDC } & \text { After top dead center } \\ \text { BTDC } & \text { Before top dead center } \\ \text { CA } & \text { Crank angle } \\ \text { HCCI } & \text { Homogeneous charge compression ignition } \\ \text { SI } & \text { Spark-ignition } \\ \text { CIDI } & \text { Compression ignition direct injection } \\ \text { LTHR } & \text { Low-temperature heat release } \\ \text { HTHR } & \text { High-temperature heat release } \\ \text { NTC } & \text { Negative temperature coefficient } \\ \text { SOI } & \text { Start of ignition }\end{array}$

\footnotetext{
* Prof, Tanta University, Faculty of Eng., Mechanical Power Eng. Department, Tanta, Egypt.

$\dagger$ Asst. Prof, Tanta University, Faculty of Eng., Mechanical Power Eng. Dep., Tanta, Egypt, medhatelkelawy@f-eng.tanta.edu.eg

Dr. Eng, Tanta University, Faculty of Eng., Mechanical Power Eng. Dep., Tanta, Egypt.

$\S$ Eng. , Delta Sugar Company, El-Hamoul, Kafr El-Sheikh, Egypt.

II Prof, Assiut University, Faculty of Eng., Mechanical Eng. Department, Assiut, Egypt.
} 


$\begin{array}{ll}\text { IVC } & \text { Inlet valve closing } \\ \text { EVO } & \text { Exhaust valve opening } \\ \text { HRR } & \text { Heat release rate } \\ \varnothing & \text { Equivalence ratio } \\ \text { TDC } & \text { Top dead center }\end{array}$

\section{Introduction}

The HCCI combustion process is combining the advantages of both spark-ignition (SI) engines and compression ignition direct injection (CIDI) engines [1]. In HCCI combustion engines, the homogenous fuel and oxidizer mixtures are compressed and self-ignited occurs in the cylinder when the mixture temperature and pressure reach fuel self-ignition as result the auto ignition takes place simultaneously at multiple locations throughout the entire combustion chamber. The mixture auto-ignites uniformly without any external ignition device such as the spark plugs or fuel injectors. The principle of HCCI engine operates at the diluted condition and HCCI combustion processes and ignitions controlled by chemical kinetic reaction rates of the mixture $[2,3]$. Therefore, controlling the timing of ignition and burning rate is more difficult in an HCCI engine compared to a conventional diesel engine.

The reactivity of fuels and their auto-ignition are the important parameter that affects HCCI combustion characteristics. Consequently, the combustion of HCCI will be influenced by controlling the temperature, pressure, and composition of the fuel and air mixture. The HCCI combustion process has the potential to improve thermal efficiency and reduce nitrogen oxides (NOx), soot emission [4]. However, there are many challenges remaining before applying HCCI to commercial use such as controlling the start of combustion and consequently lack of ignition control mechanism and a limited operating range of HCCI engine. Some methods are used to realize the control method of the mixture auto ignition and overcome the disadvantage of HCCI, such as heating the intake air [5], increasing the compression ratio [6] and reactivity using multi fuel [7]; Fuel-flexibility forms the most important characteristic of HCCI. Many types of research were focused on studying the effects of different fuel physical and chemical properties on the combustion. The use of variety types of fuels has the potential to the expansion of the HCCI operating range and controlling combustion rate of HCCI [8]. The basic idea of the use different types of fuel is the uses of fuels have different auto-ignition characteristics such as diesel fuel, Ethanol. Where diesel fuel after self-ignition will ignite ethanol vapor which together with them burns much more quickly. That causes a higher rate of heat release and improved the operating range of the engine. In this research, a mixture of ethanol fuel and diesel is used in different ratios to study the impact on HCCI engine performance at various operating conditions.

Ethanol is one of the alternative fuels that contribute to the solution of energy problems in the future. .Ethanol is a renewable fuel which can be produced by alcoholic fermentation of sugar from vegetable and agricultural products, such as corn, sugar cane, sugar beets. Ethanol contains 2-carbon atoms having the molecular formula $\mathrm{CH} 3 \mathrm{CH} 2 \mathrm{OH}$. The ethanol has a very low Cetane number which lowering the level of Cetane number in ethanol and diesel blend [8]. Lower $\mathrm{CN}$ leads to higher ignition delay and the retarded start of combustion [9, 10]. The high resistance to auto ignition, low reactivity and volatility of ethanol solve lower energy efficiency and low volatility of diesel fuel in HCCI engine. Studies on ethanol utilization in diesel engine have been continued since the1970s. The first investigation was focused on the reduction of the smoke and particulate matter in the exhaust gas. Christensen et al did the first study on ethanol fuelled HCCI engine and they have explained that ethanol is a good alternative as a gasoline fuel replacement [8][9][21]. 
In our study, The HCCI engine operates on a mixture of the diesel and ethanol fuels with dual mode combustion. N-heptane was used as a substitute for diesel fuel [11-13]. N-Heptane is a heavier paraffinic fuels (more than 4 carbons), and its similar Cetane number of diesel fuel, Therefore is often used as an auto ignition surrogate for diesel fuel and can be easily simulated in an HCCI engine [11]. The fuel properties of n-heptane and ethanol are shown in Table 1.

Table 1. Properties of $n$-heptane and ethanol fuels

\begin{tabular}{|c|c|c|}
\hline Properties & n-Heptane & Ethanol \\
\hline Chemical formula & $\mathrm{n}-\mathrm{C}_{7} \mathrm{~h}_{16}$ & $\mathrm{C}_{2} \mathrm{~h}_{5} \mathrm{oh}$ \\
\hline Density $\mathrm{Kg} / \mathrm{m}^{3}$ & 685 & 790 \\
\hline Cetane number & 53 & 11 \\
\hline Lower heating value $(\mathrm{kJ} / \mathrm{kg})$ & 42510 & 28865 \\
\hline Auto- ignition temperature $\left(\mathrm{C}^{\circ}\right)$ & 287 & 357 \\
\hline Boiling point $\mathrm{C}^{\left(\mathrm{C}^{\circ}\right)}$ & 98.4 & 78.4 \\
\hline$(\mathrm{A} / \mathrm{F})_{\text {Stoich }}$ & 15.18 & 9 \\
\hline
\end{tabular}

The principle aims for this study is to explore the impacts of ethanol added to diesel fuel on HCCI combustion characteristics at different load and premixed ratio of ethanol and n-heptane percentage. In this work the influence of engine operating parameters which is including the premixed ratio and fuel-air equivalence ratio on the combustion characteristics of HCCI engine have been studied. These effects are calculated and traced through the simulation result data of the in-cylinder pressure, temperature, and heat release at different premixed ratios of ethanoldiesel fuels blends of $0,10,20,30,40$ and $50 \%$ (by volume).

\section{Modeling Scheme}

The HCCI combustion process consists of three regimes: low temperature, intermediate temperature, and high temperature. The negative temperature coefficient (NTC) occurring at the end of low-temperature appear in the small premixed ratio of ethanol [14]. This can be observed clearly in the heat release rate (HRR) curves [20]. The diesel, ethanol and air are mixed together during the compression stroke. The combustion process is more sudden. Ethanol delays the ignition and combustion of diesel fuel and prevents damage to the engine

It was noted that an increase of ethanol in the blends decrease the pressure and temperature inside the cylinder and retard the start of ignition as a result of the cooling effect due to the vaporization of the premixed mixture of air and ethanol[15, 16]. It can be seen that HCCI combustion process has many benefits in raising the thermal efficiency and reducing the exhaust emissions. HCCI offers flexible use of multiple fuels to reduce dependence on fossil fuels. This study is carried out using a single-zone model. This model is a simplified way to represent the HCCI combustion process.

The simulated engine in this research is a 4-stroke single cylinder diesel engine. The engine speed is adjusted to be 1500 RPM during all the simulation runs. A summary of the engine specification can be found in Table 2. However, a homogeneous air and ethanol / diesel premixed mixture is formed and driven into the engine cylinder, where it is compressed and the combustion is initiated from a pilot autoignition as in a conventional diesel engine. Computer simulation of the engines is an important tool in analyzing the effect of input variables like intake pressure, temperature, and fuel mixture. It also reduces the need for expensive engine tests for engine study. There are a few kinetic mechanisms accessible from previous studies for ethanol and N-heptane [17] 
Table 2 specifications of the measured engine.

\begin{tabular}{l|l}
\hline \hline Number of engine cylinders & 1 \\
\hline Bore - Stroke mm & $100 \times 105$ \\
\hline Connecting rod & 3.714 \\
\hline Displacement $\mathrm{cm}^{3}$ & 825 \\
\hline Cycle & Four stroke \\
\hline Maximum speed RPM & 1500 \\
\hline Intake valve open & $32^{\circ}$ Before TDC \\
\hline Intake valve close & $95^{\circ}$ After TDC \\
\hline Exhaust valve open & $71^{\circ}$ After TDC \\
\hline Exhaust valve close & $32^{\circ}$ Before TDC \\
\hline \hline
\end{tabular}

Single zone model is used to simulate the HCCI engine with assumption of the thermodynamic state of the mixture is uniform inside the combustion chamber. Those means there is no variations in the temperature, pressure, or mixture composition are considered. In-cylinder fluid motion is neglected, cylinder charge was considered to behave as an ideal gas. Distribution of thermodynamic properties inside the combustion chamber was considered to be uniform; dissociation of combustion products was neglected [18]. In general, these models succeed in the discovery the effects of the fuel composition, compression ratio, varying equivalence $\mathrm{A} / \mathrm{F}$ ratio, EGR level, intake pressure and other operating parameters on the combustion process. A single-zone model can suitable to predict ignition in an HCCI engine when the initial conditions are known.

The chemical reactions within HCCI engine are simulated using detailed kinetic reaction mechanisms for describing combustion of hydrocarbon fuels of n-heptane and ethanol. The mechanism is proposed by Curran et al [19] which consist of several hundred of species and several thousand of elementary reactions approximately 554 chemical species and 2490 elementary reactions. Mechanism is used to describe the oxidation of n-heptane and ethanol as a duel fuels [12]. The single model operates between the period of inlet valve closing (IVC) and exhaust valve opening (EVO). However, the initial conditions of the combustion chamber at IVC are user to set the engine parameters and are required for the model input.

The CHEMKIN-PRO package is used to simulate the combustion process inside the cylinder of the internal combustion engine (ICE) under auto-ignition conditions. This is most relevant to the study the fuel auto-ignition behavior and engine knock in the application of the homogeneous charge compression ignition (HCCI) engines. A variety of heat-transfer correlation options are included. This package is used for solving the complex chemical kinetics problems and permits the user to calculate species concentrations, heat release rate, temperature, and pressure history of the combustion inside the engine cylinder. The global Woschni model for heat transfer has been implied for HCCI engine studies, even though the conditions in the engine vary significantly from those considered in the original work aimed at $\mathrm{CI}$ engines. Also, engine heat release analysis sub model have been used in this model to trace and study an individual cycle in the cylinder combustion. 


\section{Results and Discussion}

\subsection{Rate of Heat Release and Combustion Characteristics}

The impact of different premixed ratios of ethanol/diesel fuel blends on combustion characteristics of $\mathrm{HCC}$ is explained by analyzing the obtained data from the single zone mode simultaneously. The obtained data was collected at constant and stable engine operating conditions of the intake engine temperature and pressure.

Net n-heptane fuel is characterized by high self-ignitability and two stage ignition whereas ethanol is distinguished as a single-stage ignition. The addition of ethanol to $n$-heptane fuel does not affect the ignition behavior of $n$-heptane as shown profiles of heat release as illustrated in Figure 1. Where, the net rate of heat release for a single cylinder in the case of diesel engine fueled with various premixed ratio $0 \%, 10 \%, 20 \%, 30 \%, 40 \%, 50 \%$ (by vol.) ethanol are presented in Figure 1. From the shown data, it can be found that a two-stage combustion consisting of three regimes; low temperature, intermediate temperature, and high temperature with a negative temperature coefficient (NTC). The maximum value of the low-temperature heat release decreases and the negative temperature coefficient (NTC) period, (time between LTHR and HTHR reactions) increases with the increase of ethanol addition in the blended fuels. The ignition timing is gradually delayed with increase the ethanol addition. Higher concentrations of the ethanol in the mixture decrease the total amount of heat release. However, it can be noticed from Figure 1, the net heat release is moving towards the TDC with increase the premixed ratio of ethanol.

The effect of different premixed ratios of ethanol/n-heptane fuel blends on the in-cylinder pressure and temperature have been presented in Figure 2. The results show that, the in-cylinder peak pressure for $n$-heptane is higher compared with adding ethanol / $n$-heptane blends. The peak values of the in-cylinder pressure decreases with the increase of the premixed ratio of the ethanol due to the decrease in the mixture chemical reaction activities inside the cylinder before the combustion events. It is clear from Figure 2 that, the pressure rise decreases and the ignition time delay increase when the premixed ratio of ethanol increases. Also, the increase of the premixed ratio of ethanol retards the beginning of the combustion due to the slow down effect of ethanol in the reaction rate of $n$-heptane. Thos is because the lower value of the Cetane number of ethanol. The obtained results show that, the ETH30 and ETH40 of ethanol/nheptane fuel blends is capable to run the engine in stable HCCI combustion mode. However, at the point when the premixed ratio of ethanol is higher than $30 \%$, the combustion phase occurs before TDC, and the net heat production is released after top dead center. Therefore, the maximum in-cylinder pressure is lower as it is shown in Figure1. It is clear from Figure 2b that for the low premixed ratio of ethanol the operating range is limited by the increase in knocking probability. Those, there is too much delay at the higher premixed ratio of ethanol. In which the auto-ignition was occurred in the downward movement of the piston away from TDC which causes a high possibility of misfiring and quench happens to the flame inside the engine.

The effect of the premixed ratio of ethanol on the in-cylinder temperature can be seen in Figure 3. The peak values of the in- cylinder temperature decreased with increasing the ratio of ethanol in the mixture due to the increase of the cooling effect and latent heat of evaporation of the ethanol fuel. Figure 4 and Figure 5 shows the effect of increasing premixed ratio of ethanol added to fuel mixture on the in-cylinder maximum pressure and maximum temperature. The maximum pressure decrease from about 110 bar to 100 bar and The maximum temperature decrease from $2153 \mathrm{~K}$ to $2120 \mathrm{~K}$ with the increase premixed ratio of ethanol under the constant equivalence ratio $(\varnothing)=0.45$, due to cooling effects, The high enthalpy of vaporization and low boiling point of ethanol. 


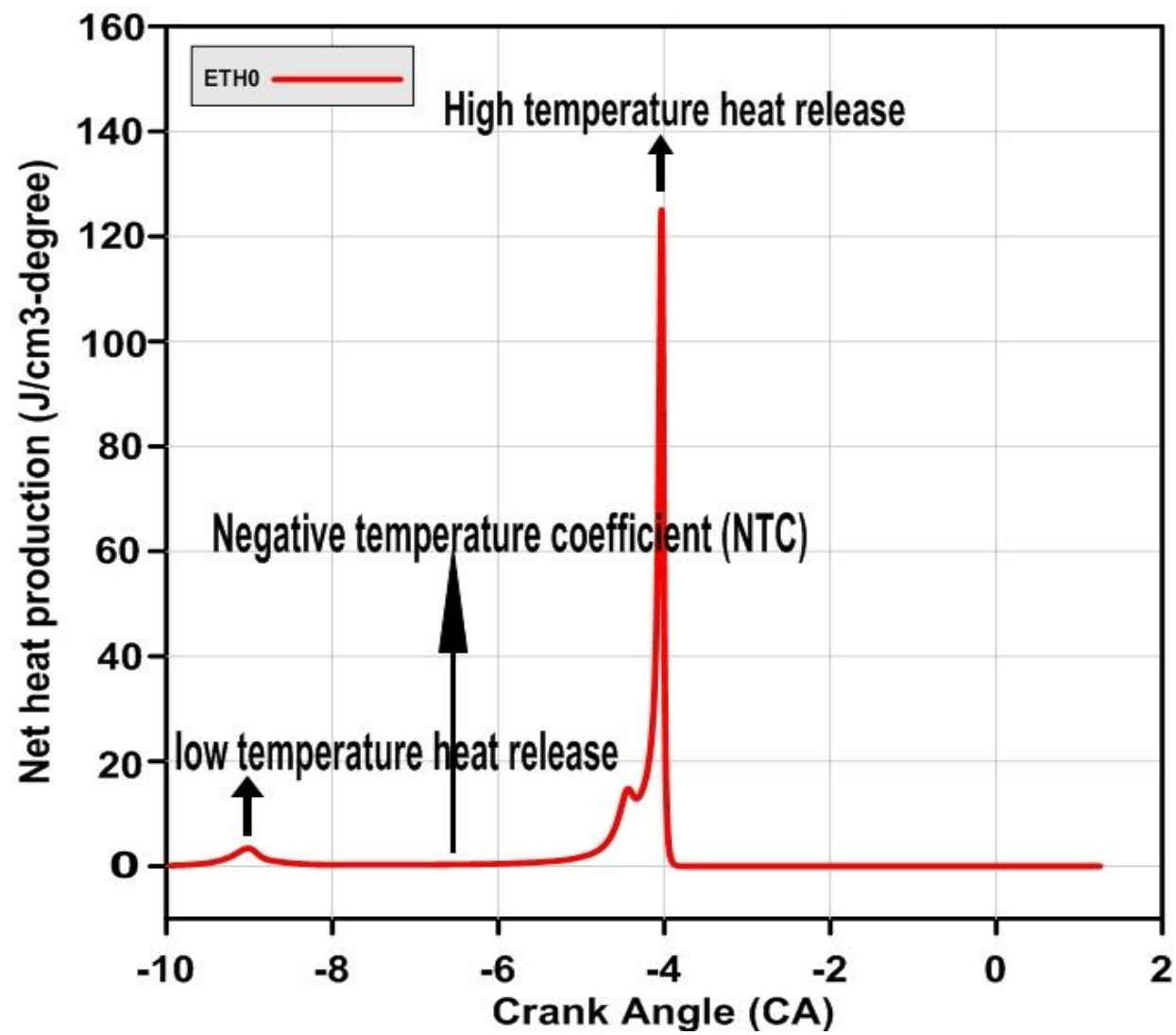

Fig. 1a. The two-stage combustion consisting of three regimes of heat release

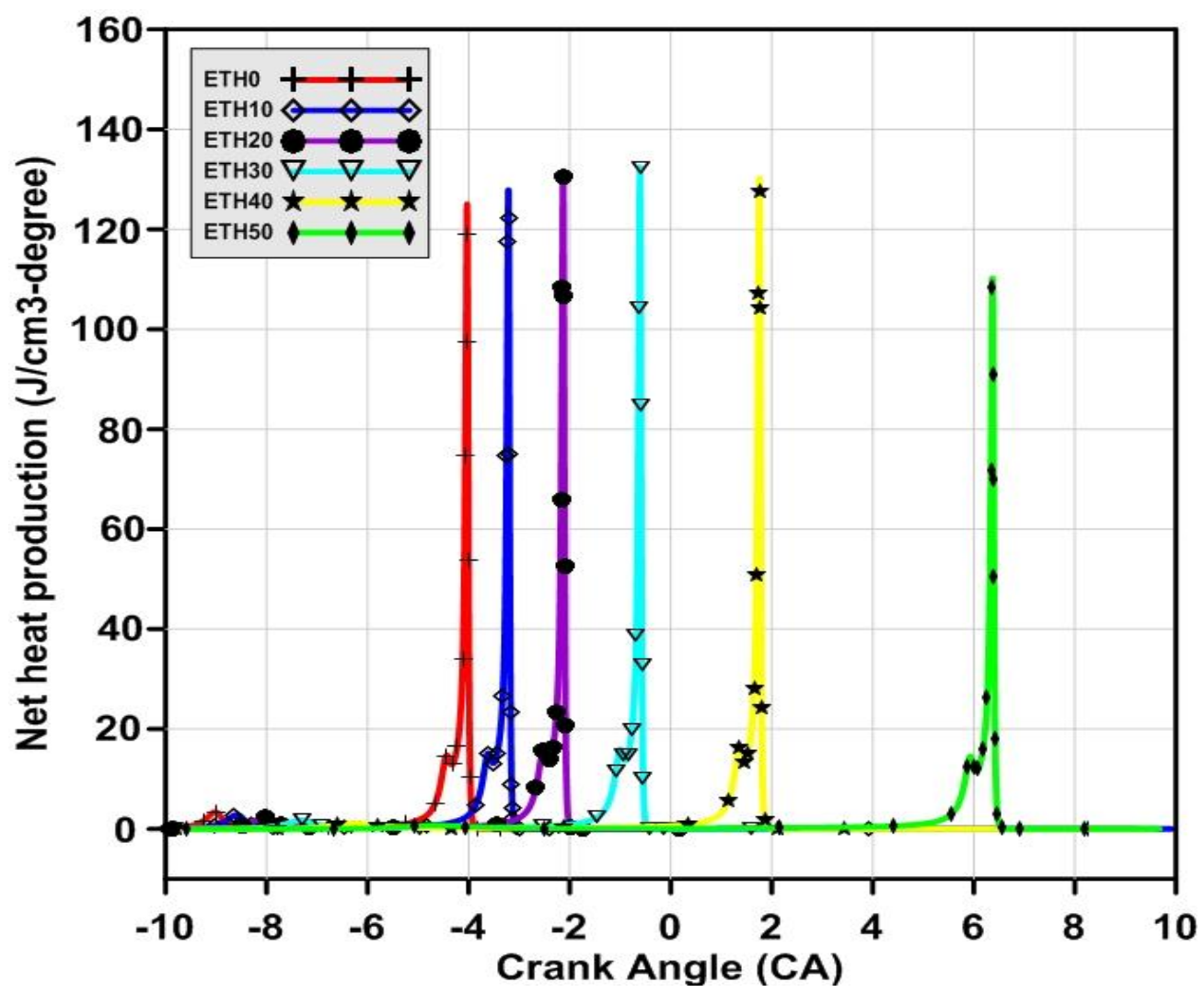

Fig. 1b. Effects of premixed ratio on rate of heat release versus crank angle at constant speed 1500 RPM, equivalence ratio $(\varnothing)=0.45$ 


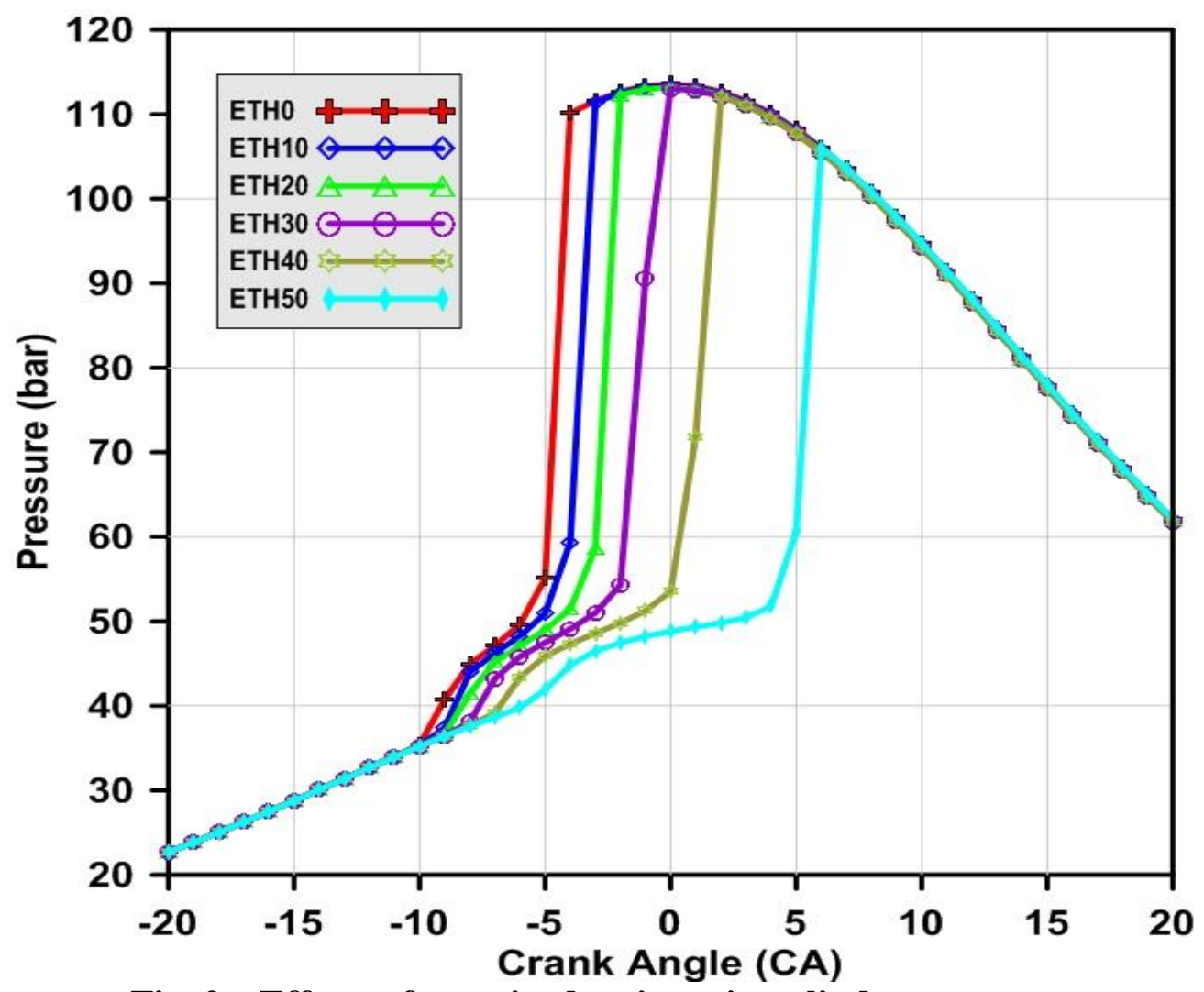

Fig. 2a. Effects of premixed ratio on in-cylinder pressures constant speed $1500 \mathrm{RPM}$ and $\emptyset=0.45$

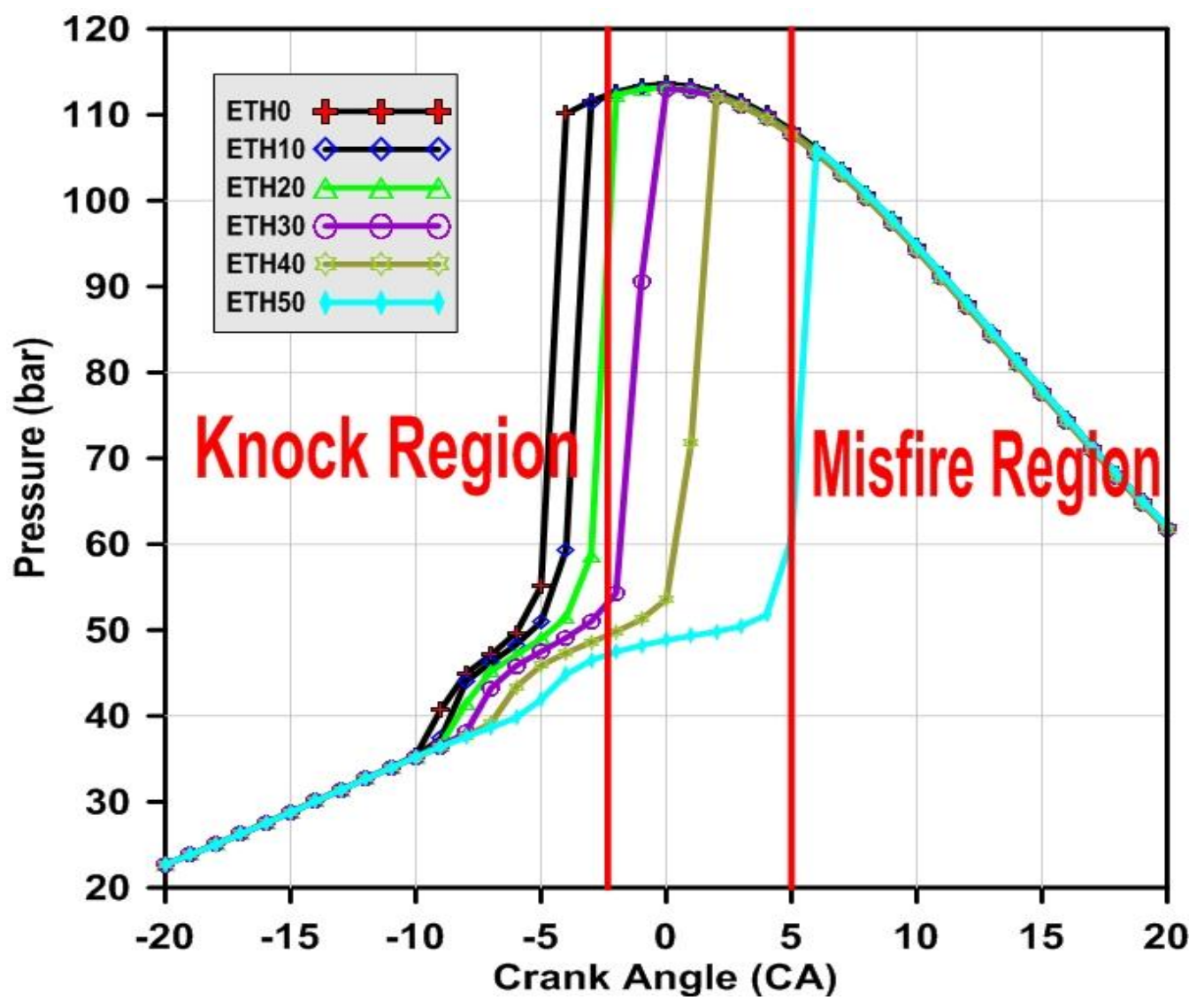

Fig. $2 \mathrm{~b}$. HCCI operating range for different premixed ratio of Ethanol/n-heptane blends for equivalence ratio $(\varnothing)=0.45$. 


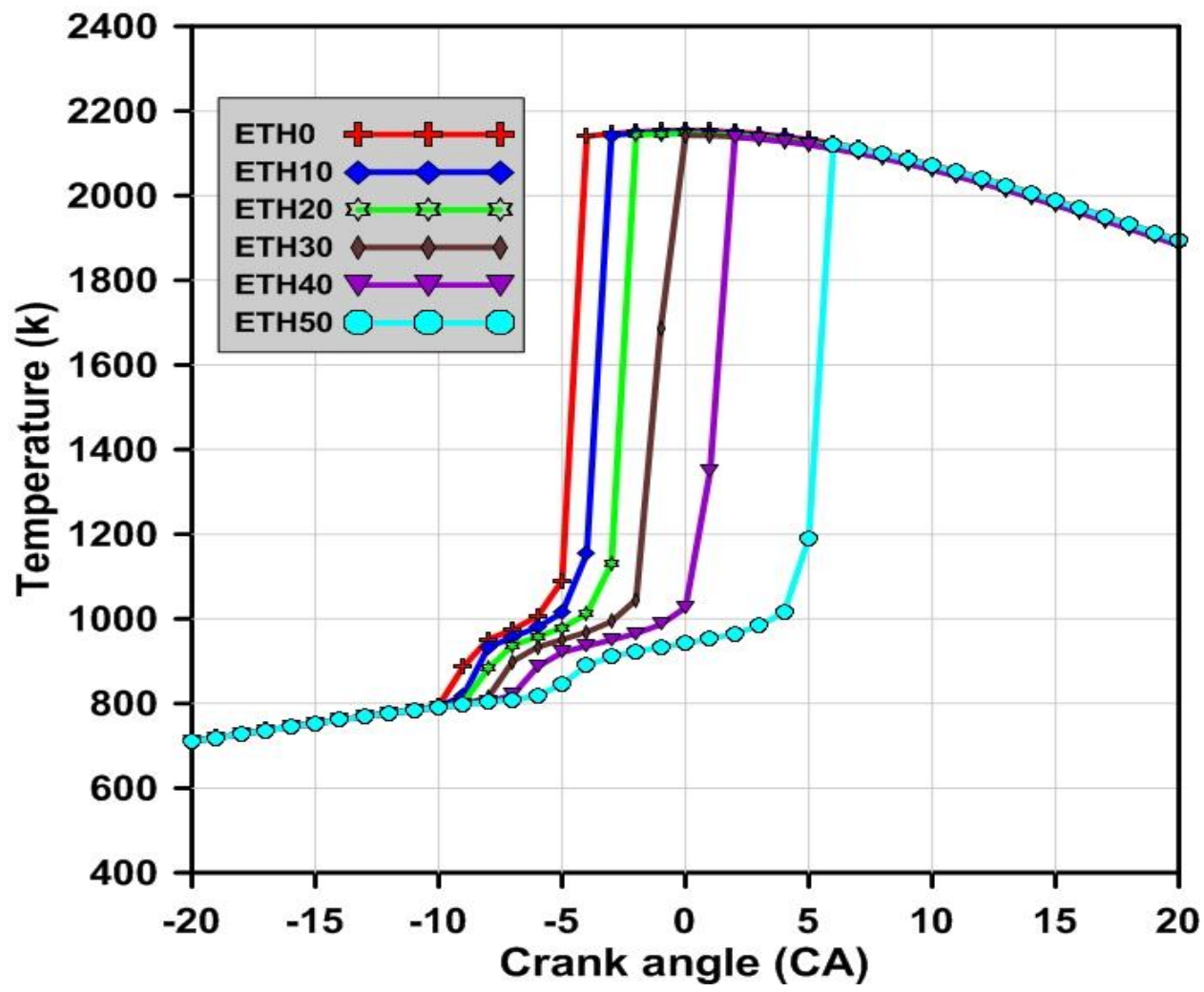

Fig 3. Effects of premixed ratio on in-cylinder temperature at constant speed $1500 \mathrm{RPM}$ and $\emptyset=0.45$

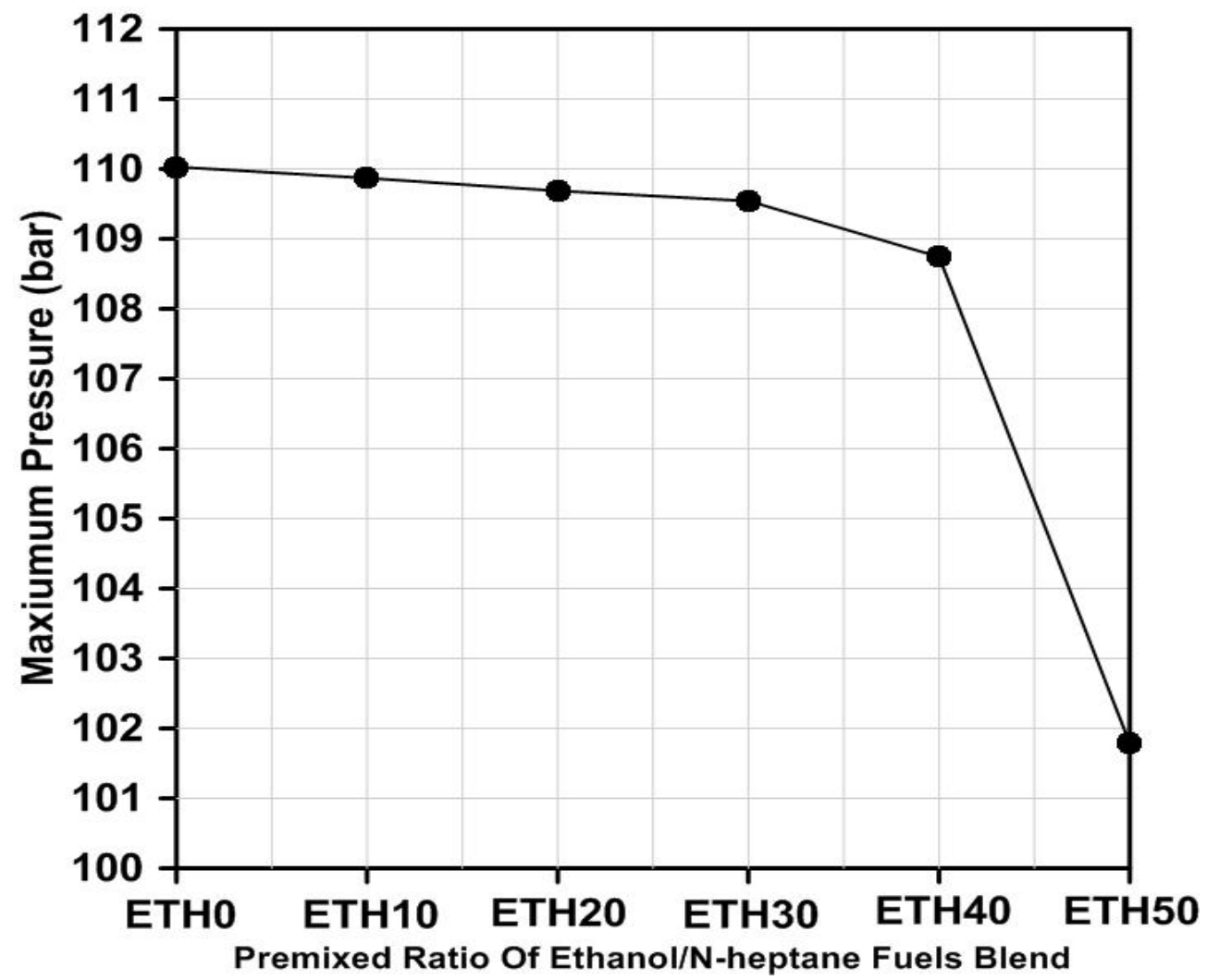

Fig. 4. Maximum cylinder pressure at different premixed ratio of ethanol/n-heptane fuels blend at constant speed $1500 \mathrm{RPM}$, equivalence ratio $(\varnothing)=0.45$. 




Fig. 5. Maximum gas temperature at different premixed ratio ethanol/n-heptane fuels blend at constant speed $1500 \mathrm{RPM}$, equivalence ratio $(\emptyset)=0.45$.

\subsection{Effect of Equivalence Ratio on Combustion Characteristics}

It is observed from Figure 6 that the maximum pressure depended on the value of equivalence ratio where the higher equivalence ratio $(\varnothing)$ leads to increase in peak pressure. However, the maximum pressure decreases as the equivalence ratio becomes smaller because the richer mixture leads to higher fuel amount burned and higher in-cylinder pressure. The effect of the premixed ratio of the ethanol on the in-cylinder temperature and pressure can be seen in Figure 6 and Figure 7. Those, with increasing the value of premixed ratio of ethanol the maximum temperature and pressure of the in-cylinder are decrease. Also, the reaction activity of the incylinder mixture would be decreased with the increase of the ratio of ethanol in the fuel mixture.

It can be seen also from Figure 6 that the maximum pressure is extremely high for rich fuelair mixtures. The maximum gas temperature inside the combustion chamber is connected significantly with the emissions concentration of exhaust. It is clear that from Figure 7, with increasing the premixed ratio of ethanol the maximum temperature inside the combustion chamber will decreases as a result of the high heat of vaporization of ethanol. It can be noticed from the Figure 5 that the maximum gas temperature in the combustion chamber is maximized in the case of richest mixture. As the mixture becomes lean, the maximum gas temperature decreases for all ethanol/n-heptane fuel blends. The observed results of Figure 8 show that the crank angle position of maximum pressure is arrive at near TDC and decrease after TDC with increase the equivalence ratio. However, the overall reaction activity of the in-cylinder mixture would increase with increasing the premixed ratio of the ethanol, and the in-cylinder maximum pressure would occur away from TDC. 


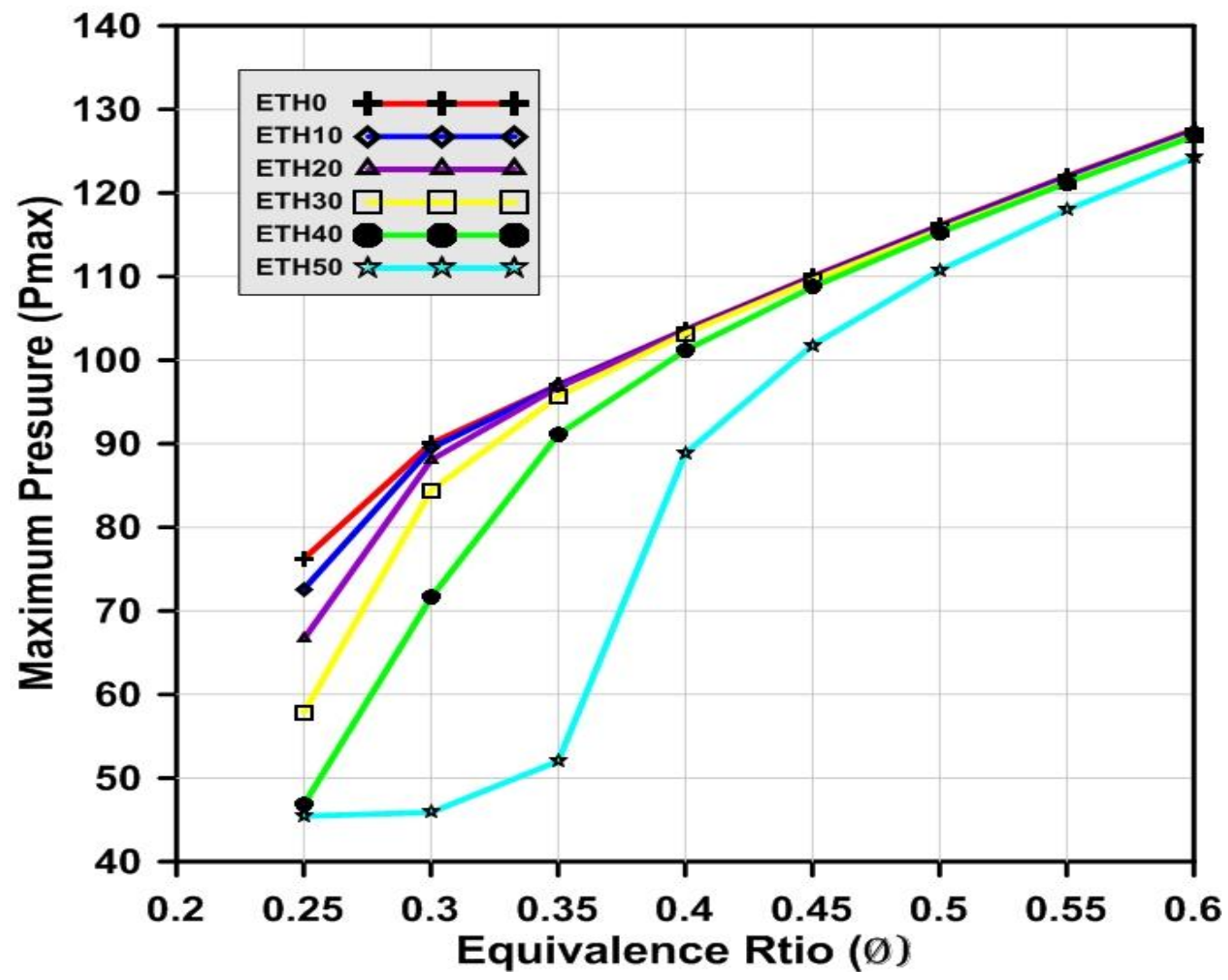

Fig. 6.The in-cylinder maximum pressure for different equivalence ratio

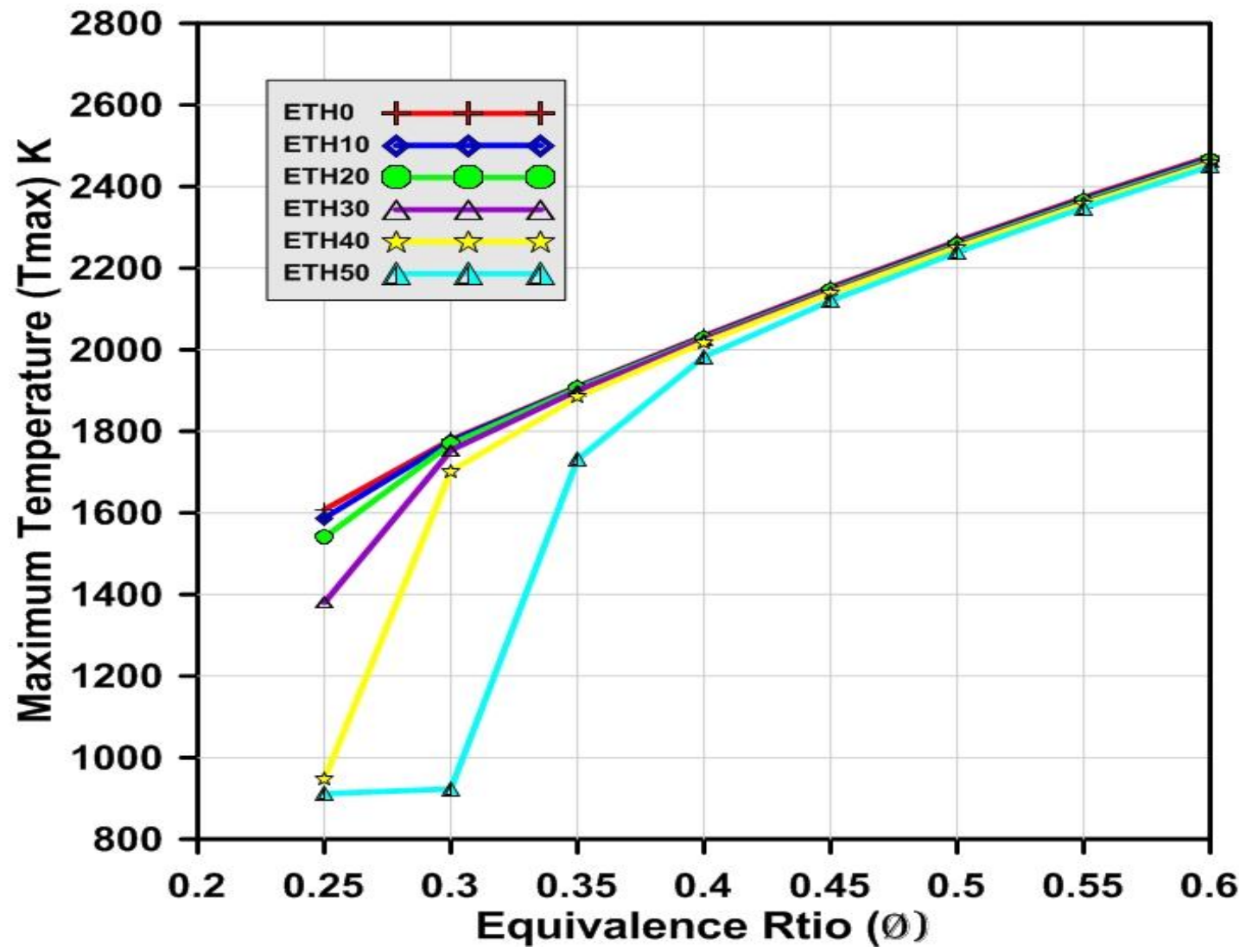

Fig. 7. Maximum gas temperature inside the cylinder at different equivalence ratio 


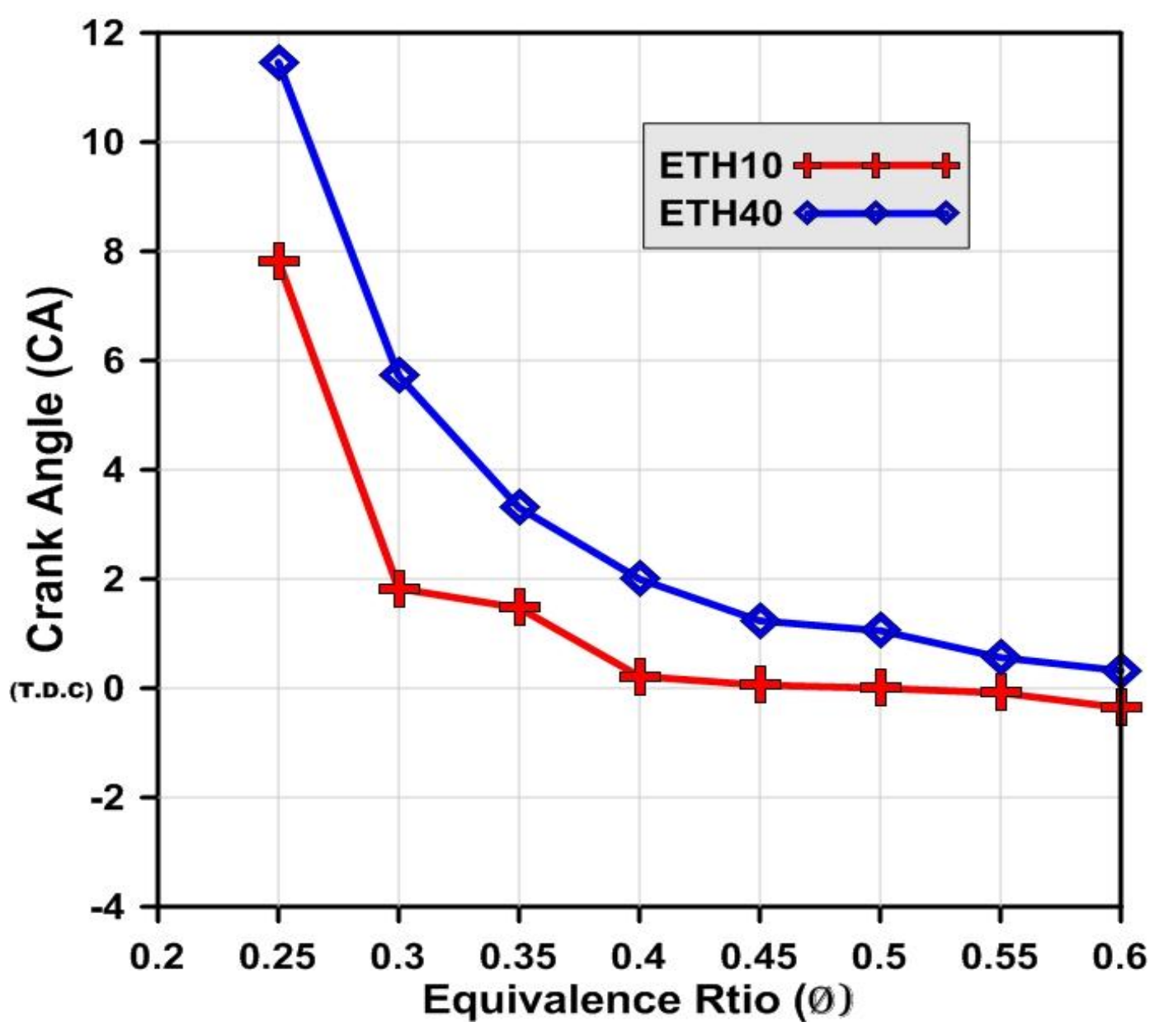

Fig. 8. Crank angle at maximum pressure for HCCI engine at different Equivalence Ratio (Ø)

\subsection{Starting of Combustion (SOC) and Combustion Duration}

The Start and end of combustion can be defined at the crank angle when $10 \%$ and $90 \%$ of the cumulative heat release (HR) have taken place respectively. The combustion duration is defined as the time between $10 \%$ and $90 \%$ cumulative heat release. The start of combustion is affected by the value of the equivalent ratio for all fuel mixtures. Figure 9 shows the modeled start of ignition timing with various equivalence ratios. The start of ignition decreases almost linearly with the mixture of equivalence ratio, where increasing equivalence ratio delays the start of ignition. The ignition timing is gradually delayed to the top dead center (TDC) by the ethanol addition. The retardation of the ignition timing due to the increase in the premixed ratio of the ethanol is caused by the very low Cetane number of ethanol which prohibits ignition. In HCCI combustion, the start of combustion depends on chemical kinetics, which relies on the pressure and temperature inside the combustion chamber.

At constant load and equivalence ratio as shown in Figure $\mathbf{1 0}$ the increase of ethanol in the mixture retard the start of ignition. The variation of the start of combustion and combustion duration in crank angle in HCCI mode at constant load or equivalence ratio is represented in Figure10. The $90 \%$ of the mass-burn-fraction can be expressed as the quantitative value close to the end of combustion in the cylinder. It is observed that as the premixed ratio of ethanol increases the crank angle for $90 \%$ of the mass-burn-fraction moves further away after TDC and vice versa. 


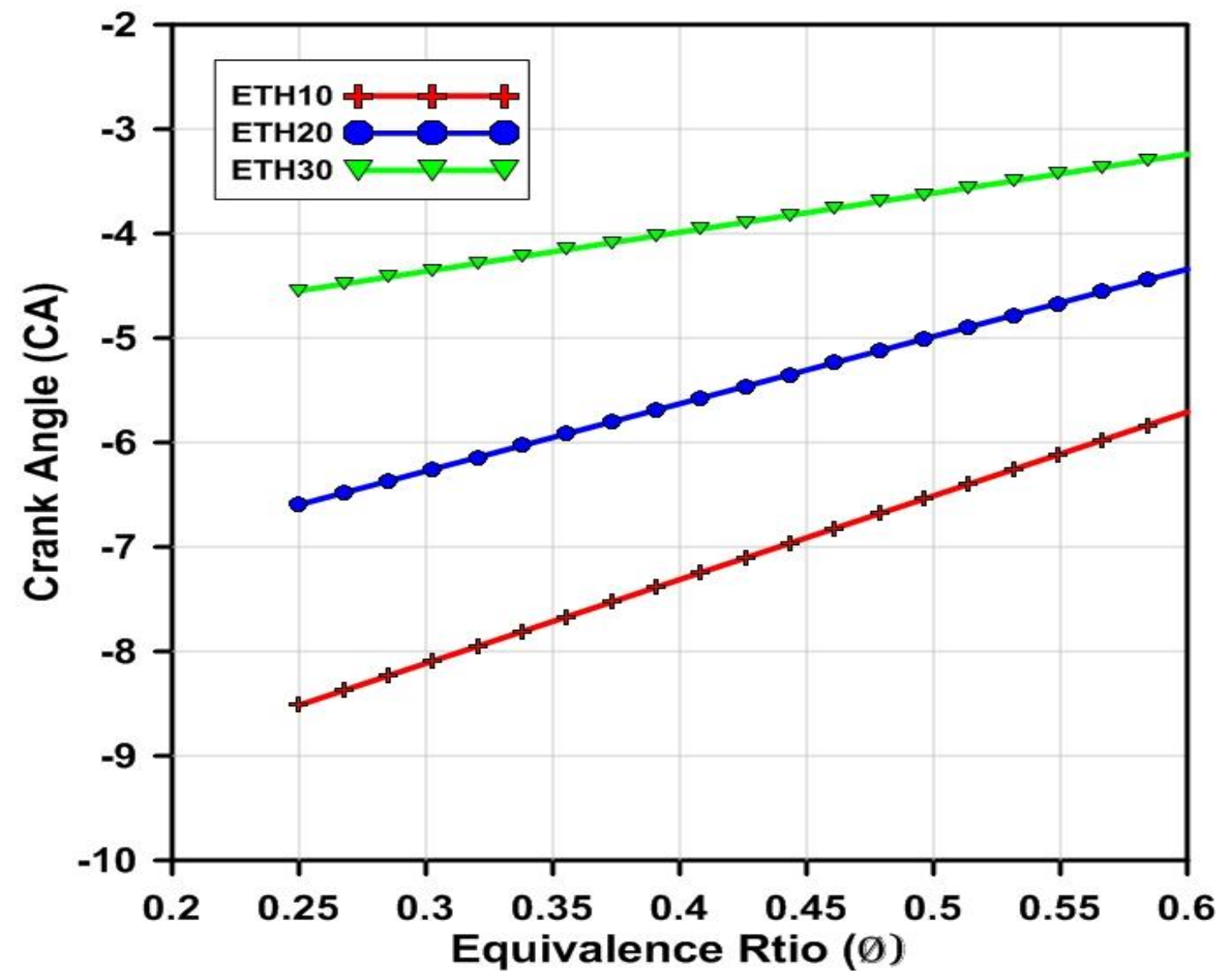

Fig. 9. The effect of equivalence ratio on the start of ignition

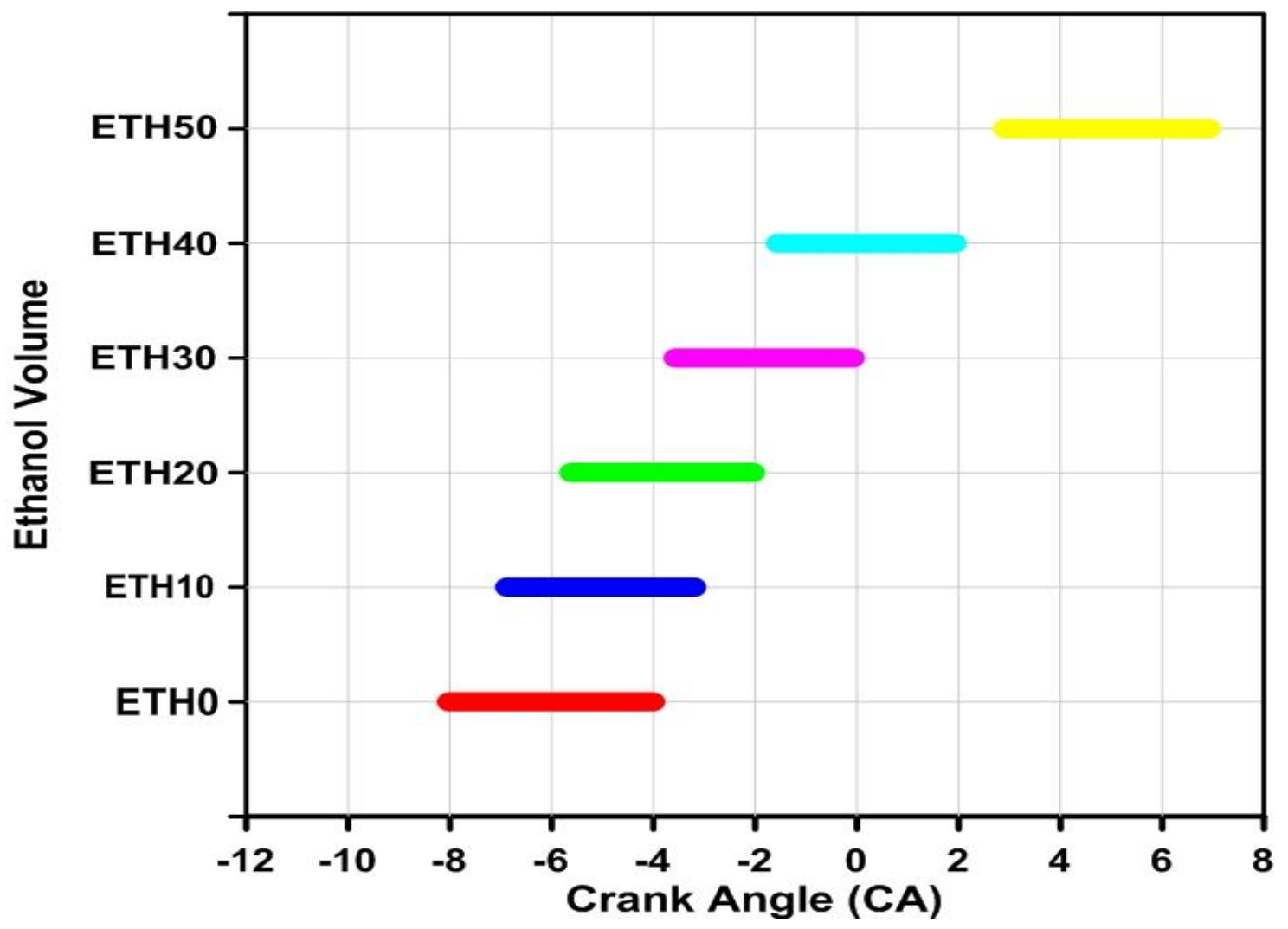

Fig. 10. The effect of different premixed ratio of ethanol on combustion duration and $\mathrm{SOI}$ at constant equivalence ratio $(\emptyset)=0.45$ 
Figure 11 shows the influence of the increasing equivalenceratio on the duration of combustion at different premixed ratio of ethanol. It is observed from Figure11 that the duration of combustion is the highest for the lean mixture. As the mixture becomes richest, the duration of combustion is decreased. In the case of the constant equivalence ratio, the duration of combustion decreases with the ethanol blend percentage increases as result of low cetane number of ethanol.

\section{Modeling of HCCI Engine Validation}

To validate the single zone model and the selection of the chemical-kinetic mechanism for $\mathrm{n}$ heptane /ethanol combustion the experimental data of $\mathrm{Lu}$ " Xingcai [21] have been used to evaluate the model results. However, the model and experimental results show good agreement as presented in Figure 12. The detailed chemical kinetic mechanism for n-heptane proposed by Curran et al [17] which proved its reliability in comparison with experimental data. This kinetic mechanism can be applied to HCCI engine combustion to study the effect of the fuel mixture of ethanol/n-heptane blends on the engine performance.

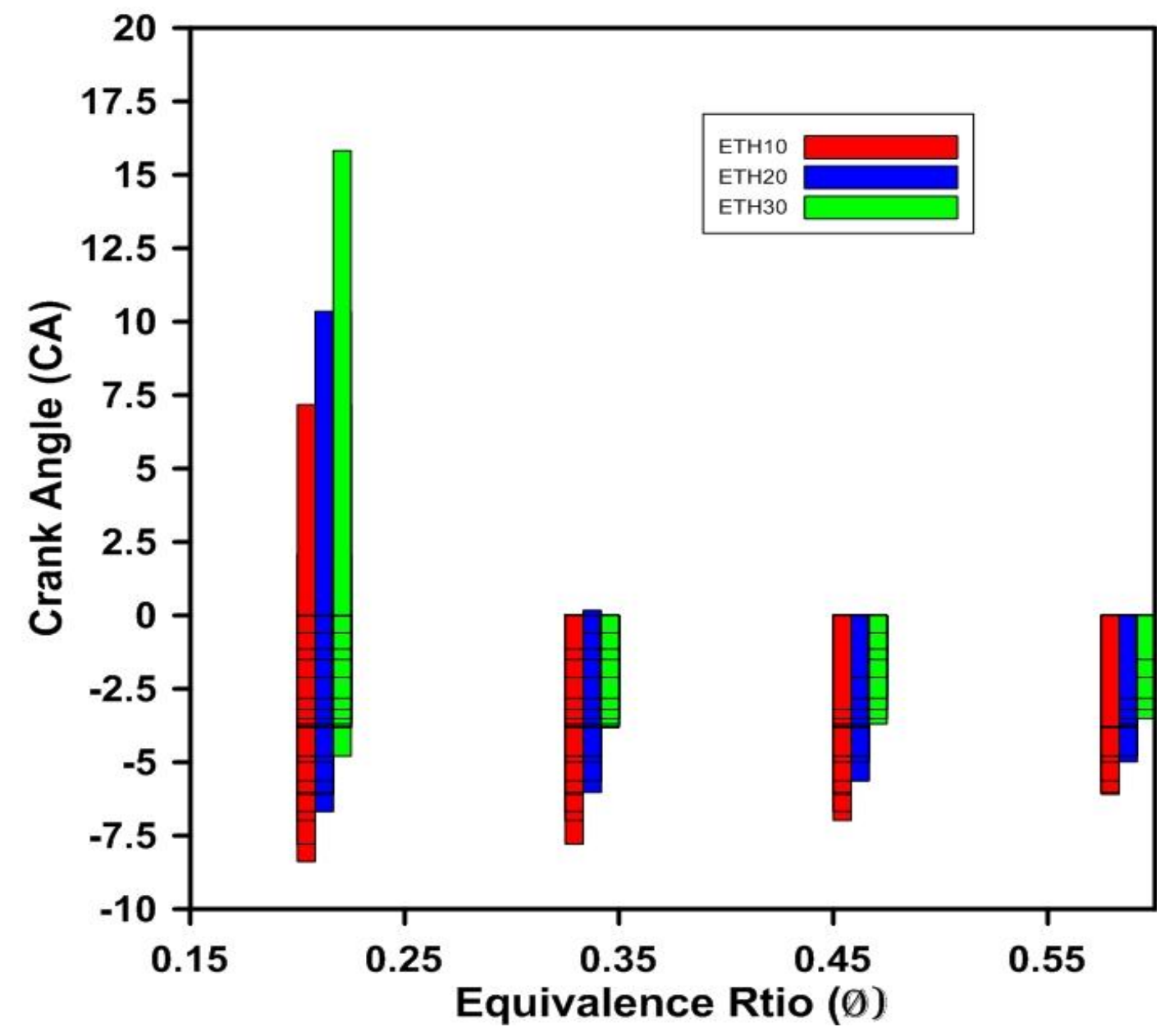

Fig. 11. The effect of equivalence ratio on the duration at different premixed ratio of ethanol and different equivalence ratio 


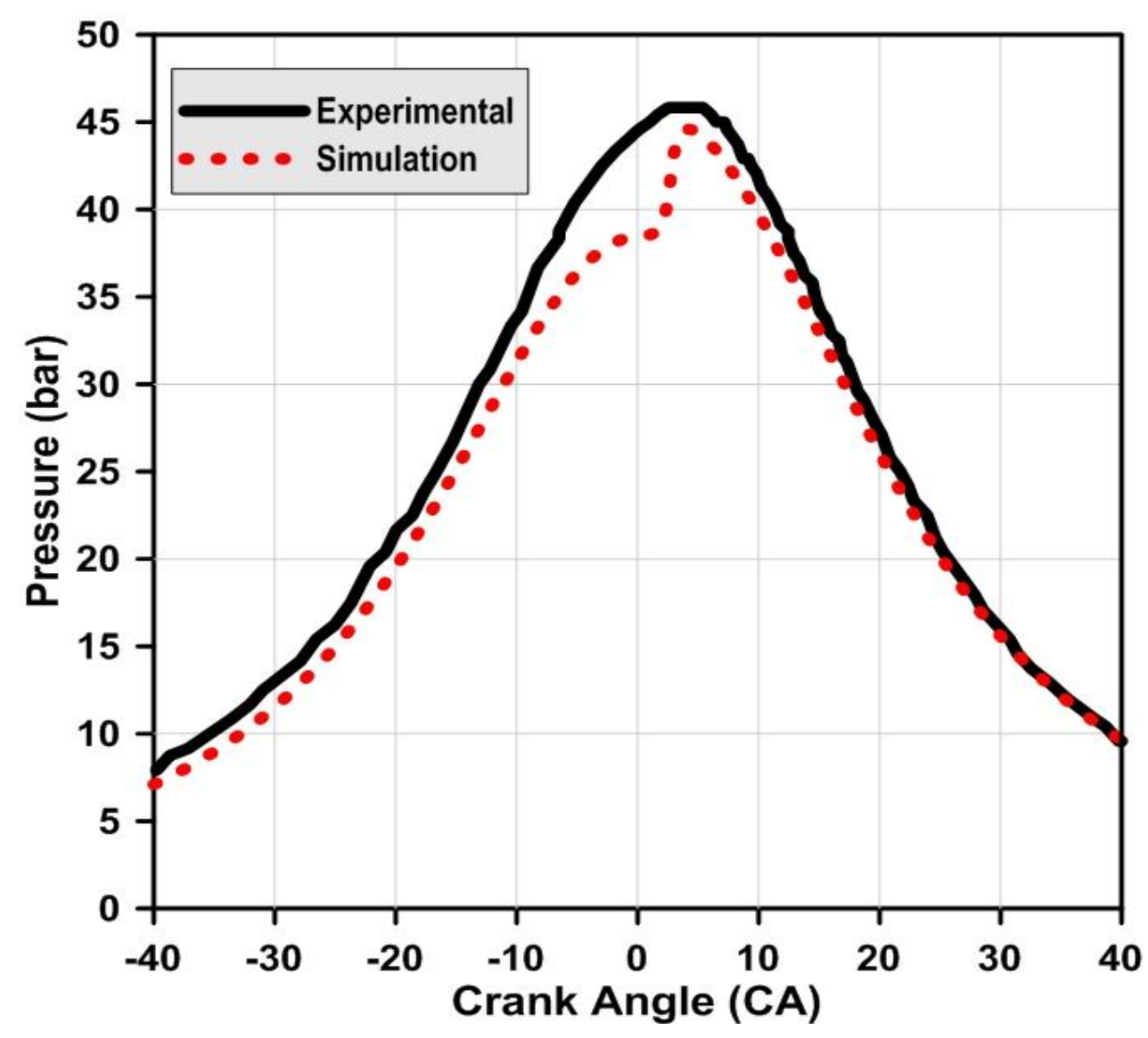

Fig. 12. Comparison of the experiment and simulation on cylinder pressure

\section{Conclusions}

In this work HCCI engine is simulated using single zone model for finding the performance of the engine when it works by the different premixed ratio of Ethanol/diesel fuel blends. The following summarizes the important conclusions from this study:

1. In the HCCI combustion, chemical kinetic control the ignition and the combustion is very sensitive to the premixed ratio of Ethanol/diesel mixture and equivalence ratio which can be used as an effective control variable for combustion phasing

2. Stable HCCI combustion is achieved in the range of the premixed ratio of ethanol (ETH30ETH40) at equivalence ratio 0.45 .

3. HCCI combustion with diesel/Ethanol dual fuel is a 3-stage combustion process consisting of cool flame. And the total heat releases decrease with the increasing the premixed ratio of ethanol due to the increase of cooling effect and latent heat of evaporation of ethanol.

4. The increase of the premixed ratio of ethanol will decrease the peak in-cylinder pressure and temperature.

5. The addition of ethanol in diesel HCCI will cause a retard in combustion events.

6. It is found that by increasing the mass fraction of ethanol in the blends, the ignition timing delay is retard and the combustion duration was decreases.

\section{Acknowledgment}

This work was supported by the Tanta University Research Fund under the research grant (code: cod-tu; 03-15-02). 


\section{References}

1. Vuilleumier, D., et al., Intermediate temperature heat release in an HCCI engine fueled by ethanol/n-heptane mixtures: An experimental and modeling study, Combustion and flame, 2014. 161(3): p. 680-695.

2. Motyl, K. and T.J. Rychter, HCCI engine-a preliminary analysis, Journal of KONES Internal Combustion Engines, 2003. 10(3-4).

3. Flowers, D.L., Combustion in Homogeneous Charge Compression Ignition Engines: Experiments and Detailed Chemical Kinetic Simulations, 2002, Lawrence Livermore National Lab., CA (US).

4. Sjöberg, M. and J.E. Dec, Effects of EGR and its constituents on HCCI autoignition of ethanol, Proceedings of the Combustion Institute, 2011. 33(2): p. 3031-3038.

5. Haraldsson, G., et al., HCCI closed-loop combustion control using fast thermal management, 2004, SAE Technical Paper.

6. Ryan, T.W., T.J. Callahan, and D. Mehta, HCCI in variable compression ratio engineeffects of engine variables, 2004, SAE Technical Paper.

7. Aceves, S.M., et al., Fuel and additive characterization for HCCI combustion, 2003, SAE Technical Paper.

8. Rakopoulos, C., K. Antonopoulos, and D. Rakopoulos, Experimental heat release analysis and emissions of a HSDI diesel engine fueled with ethanol-diesel fuel blends. Energy, 2007, 32(10): p. 1791-1808.

9. Bannikov, M., S.E. Gillani, and I. Vasilev, EFFECT OF ALCOHOL ADDITIVES ON DIESEL ENGINE PERFORMANCE AND EMISSIONS.

10. Atmanli, A., Effects of a cetane improver on fuel properties and engine characteristics of a diesel engine fueled with the blends of diesel, hazelnut oil and higher carbon alcohol. Fuel, 2016, 172: p. 209-217.

11. Lü, X., et al., Experimental study and chemical analysis of n-heptane homogeneous charge compression ignition combustion with port injection of reaction inhibitors. Combustion and Flame, 2007, 149(3): p. 261-270.

12. Saisirirat, P., et al., Spectroscopic measurements of low-temperature heat release for homogeneous combustion compression ignition (HCCI) n-heptane/alcohol mixture combustion' Energy \& Fuels, 2010. 24(10): p. 5404-5409.

13. Curran, H.J., et al. Oxidation of automotive primary reference fuels at elevated pressures. in Symposium (International) on Combustion. 1998. Elsevier.

14. Visakhamoorthy, S., Modeling of Biofuelled HCCI Engines with a Parallel Multizone Model. 2011.

15. Gargiulo, V., et al., Chemico-physical features of soot emitted from a dual-fuel ethanoldiesel system. Fuel, 2015, 150: p. 154-161.

16. Asad, U., et al., Ethanol-fueled low temperature combustion: A pathway to clean and efficient diesel engine cycles' Applied Energy, 2015. 157: p. 838-850.

17. Curran, H.J., et al. 'A comprehensive modeling study of n-heptane oxidation' Combustion and Flame, 1998. 114(1): p. 149-177.

18. Maurya, R.K. and A.K. Agarwal, Experimental study of combustion and emission characteristics of ethanol fuelled port injected homogeneous charge compression ignition (HCCI) combustion engine' Applied Energy, 2011. 88(4): p. 1169-1180.

19. Mehl, M., et al., Kinetic modeling of gasoline surrogate components and mixtures under engine conditions' Proceedings of the Combustion Institute, 2011. 33(1): p. 193-200.

20. Davies, V.A., Autoignition Study of Ethanol and Heptane in a Rapid Compression Machine, 2015, the University of Akron.

21. Lü, X., et al., Experimental study on the auto-ignition and combustion characteristics in the homogeneous charge compression ignition (HCCI) combustion operation with ethanol/n-heptane blend fuels by port injection. Fuel, 2006, 85(17): p. 2622-2631. 